\title{
CAMPo ACADÊmico, História ANTIGa e Ensino: COMENTÁRIOS EM TORNO DO PRESENTE E FUTURO DE UMA ÁREA.
}

Guilherme Moerbeck ${ }^{1}$

O comentário que segue tem como objetivo pôr em relevo algumas questões que foram surgindo na leitura do artigo "O ensino e a pesquisa em História Antiga no Brasil: Reflexões a partir dos dados da Plataforma Lattes”, escrito pelo professor Dominique Santos, docente na Universidade Regional de Blumenau, bem como de seus coautores, integrantes do LABEAM - Laboratório Blumenauense de Estudos Antigos e Medievais. Como todo comentário, acabo ressaltando ao leitor que, mais do que fazer uma avaliação sistemática do artigo em questão, teço aqui uma leitura bem mais seletiva. Dessa maneira, chamarei atenção tão somente aos aspectos para os quais eu possa contribuir, de alguma forma, aos prolongamentos da reflexão dos autores.

Em seus prolegômenos, o texto discute o processo de institucionalização da História Antiga no país, em especial o da formação da noção de clássico durante o século XIX, que teve absorção nos currículos escolares até a formação da primeira cátedra na Universidade de São Paulo. Hoje, quem desenvolve interessante pesquisa sobre essas questões é o professor Luís Ernesto Barnabé, da UENP, especialmente sobre a figura de Justiniano da Rocha e alguns dos primeiros manuais escolares de História - inclusive Antiga, produzidos para o Colégio Pedro II, no Rio de Janeiro (Barnabé, 2016).

A partir de então, os autores comentam, em termos gerais, o fortalecimento da área de História Antiga e seu crescimento, inclusive institucional, por meio do GTHA e da SBEC, que atingiu, seletivamente, e em velocidades bem distintas, as regiões brasileiras. Note-se, ainda, o que se pode chamar de pilares da História Antiga no país. Refiro-me a nomes como os de Ciro Flamarion Cardoso, Neyde Theml e Haiganuch Sarian, que talvez tenham sido os mais importantes formadores de historiadores e arqueólogos da Antiguidade no

\footnotetext{
${ }^{1}$ Desenvolve no MAE/USP um projeto de pós-doutorado, sob supervisão da Prof ${ }^{a}$. Maria Beatriz Borba Florenzano e é Professor Adjunto de História da Arte e Arquitetura no Departamento de Arquitetura e Urbanismo da Universidade do Estado do Rio de Janeiro (ESDI/UERJ). Membro do LABECA/MAE/USP e do Leitorado Antiguo/UPE. Bolsista PDJ do CNPq.
} 
país a partir da década de 1970. Seguindo essa trilha, já em uma segunda geração não menos importante, temos nomes de professores na ativa, como os de Norberto Guarinello, Maria Beatriz Florenzano e Pedro Paulo Funari, apenas para citar as escolas em torno da USP e da UNICAMP.

Se por um lado, como alguns docentes de diversas gerações ressaltam, houve forte processo de crescimento de publicações, eventos, multiplicação de temáticas em História Antiga, por outro, ocorre de forma concomitante, algo que deve instar os integrantes dessa área à reflexão (Faversani e Campos, 2009; Silva, 2010; Gonçalves e Silva, 2008). Refiro-me a um efeito colateral desse "crescimento geométrico" da área, uma espécie de esvaziamento de congressos espero não estar pesando a mão aqui - e a falta de diálogo (ou a necessidade de aprofundamento) com os colegas que trabalham no Ensino Básico. Essas conversas aumentaram, forçosamente, por conta dos desdobramentos da primeira versão da área de História para a Base Nacional Curricular Comum, que praticamente excluía toda e qualquer reflexão no Ensino Básico sobre a Antiguidade e o Medievo.

O resultado dessa aproximação dos Historiadores da Antiguidade que lecionam exclusivamente no Ensino Superior das relevantes questões do Ensino Básico nacional possui um efeito muito benéfico: abrir os olhos dos pesquisadores e doutores que atuam nos cursos de graduação e pós-graduação para a importância do Ensino Escolar em relação à própria academia. A desconfortável realidade, após tantos debates, é a de que o mundo universitário ainda carece de uma verdadeira troca com os profissionais que atuam nas escolas. Se isso não acontecer, corre-se o risco de mantermos uma espécie de "diálogo de surdos" quanto a essa questão tão importante. Felizmente, estamos avançando, seja nas preocupações demonstradas na última reunião do GTHA, de novembro de 2016, no Rio de Janeiro, seja pelo importantíssimo papel do ProfHistória em nível nacional.

O objetivo fundamental dos autores da pesquisa era o de reunir e sistematizar dados para formar indicadores da produção acadêmica: formação e experiências fora e no país; tudo isso a partir dos currículos formatados na Plataforma Lattes, do CNPq. Nesse sentido, o trabalho, sem sombra de dúvida, foi muito bem-sucedido. 
Os meus comentários, a partir de agora, focar-se-ão em dois aspectos principais: o primeiro eu chamo de questões epistemológicas de abordagem e o segundo é uma discussão sobre a possível amplificação dos debates para uma área que vem crescendo, ainda que timidamente, o Ensino de História Antiga, especialmente o escolar.

Um dos autores que me parecem mais convenientes a um exame da produção intelectual e da configuração de uma área acadêmica é Pierre Bourdieu. Este foi muito influenciado, no início de sua carreira, pelo antropólogo Claude Lévi-Strauss e pelo linguista Ferdinand de Saussure e seus pensamentos estruturais. O primeiro influencia Bourdieu na ideia de habitus - regras de transformação não conscientes que determinam o comportamento dos sujeitos, segundo o próprio autor (Bourdieu, 2009, p. 87):

Os condicionamentos associados a uma classe particular de condições de existência produzem habitus, sistemas e disposições duráveis e transponíveis, estruturas estruturadas predispostas a funcionar como estruturas estruturantes, ou seja, como princípios geradores e organizadores de práticas e de representações que podem ser objetivamente adaptadas ao seu objetivo sem supor a intenção consciente de fins e o domínio expresso das operações necessárias para alcançá-los, objetivamente 'reguladas' e 'regulares' sem em nada ser o produto da obediência a algumas regras e, sendo tudo isso, coletivamente orquestradas sem ser produto da ação organizadora de um maestro.

Pode-se pensar o habitus em relação ao mundo prático, como sistema de estruturas cognitivas motivadoras da ação social. É um mundo de fins já realizados e, embora possam ser arbitrários, tendem a aparecer como necessários e até naturais (Moerbeck, no prelo, p. 21). O segundo influencia a noção de campo que consiste em uma estrutura de "relações objetivas entre as posições ocupadas [pelos] agentes que determinam a forma de [suas] interações” (Bourdieu, 2004, p. 66). Bourdieu se inspira na noção weberiana de que há um processo contínuo de diferenciação nas esferas sociais e de criação de especialistas com o advento da modernidade e do processo de racionalização. $\mathrm{O}$ campo deve ser pensado sempre como uma arena de lutas onde são estabelecidas relações de poder entre os atores. Assim, pode-se falar em campo artístico, político, mas o que parece interessar de forma crucial ao trabalho do artigo que ora comento é a noção de campo científico. 
A bem da verdade, a estratégia de Bourdieu pouco a pouco foi se distanciando do estruturalismo, mas sem nunca o abandonar de todo. A teoria central de Bourdieu se concentrou na noção de habitus e dos diversos campos especializados da vida social no mundo moderno. Em todos esses campos havia relações de poder e uma dada estrutura de poder específico que orientavam as relações sociais. As reflexões de Bourdieu transitam entre a ação e a estrutura, tentando uma síntese possível entre essas duas categorias (Domingues, 2008).

Ao lado das noções apresentadas, surgem conceitos como os de poder simbólico e illusio, bem como no que se refere às formas de consagração acadêmica e aos seus próprios rituais de passagem (Bourdieu, 2003a, 2004 e 2010). Em todo campo, ocorre um processo de autonomização nem sempre pleno e criação de regras internas de legitimação e consagração. Mas fato é que se tomarmos a área de História, evidentemente poderia ser outra qualquer, veremos que as regras instituídas do jogo acadêmico devem ser respeitadas e nelas se deposita confiança e crença; nas suas formas de reprodução e de criação de posições por onde operam as relações de poder de maneira mais capilar.

Falando um pouco mais especificamente sobre o mundo ao qual a pesquisa de Dominique Santos et al. se referem, tem-se desde 1976, um artigo muito interessante chamado "Le champ scientifique", publicado nas Actes de la Recherche em Sciences Sociales e que conta com tradução para o português. Sem querer me estender em demasia, aponto para alguns elementos que subjazem o discurso dos autores do artigo. Isso significa dizer que, partindo dos dados colhidos de maneira tão sistemática, poder-se-ia avançar e tentar compreender as formas de divisão do poder dentro do universo acadêmico. Assim, se poderia entender as maneiras pelas quais se dá esse jogo de luta concorrencial em torno do monopólio da competência científica e das formas variadas de acumulação de capital simbólico no caso brasileiro, mas que é não menos relevante alhures; contabilizada em indexações, participação em bancas, orientações entre outras.

Esse tipo de indagação nos levaria a respostas, quiçá numa outra escala mais espinhosa inclusive, que poderiam explicar menos a quantidade, mas o que antecede à escolha que forma "essas quantidades" lattificadas, adentrando-se, assim, noutro patamar, que julgo ajudar a explicar melhor o processo de estruturação e fortalecimento da História Antiga como área de pesquisa. 
Os autores apontam com correção, por meio da leitura de Maria Beatriz Florenzano, Pedro Paulo Funari e Renata Garraffoni, o porquê do maior interesse pelos mundos greco-romanos do que por outros "mundos antigos". A formação dos estados nacionais, a invenção do mundo ocidental em detrimento do oriente despótico e as heranças curriculares são parte desse processo (Florenzano, 2008; Funari e Garraffoni, 2004; cf. também Goody, 2008).

Outra parte, não respondida, até porque não perguntada pelos autores, tem a ver com as formas pelas quais se formaram os quadros universitários em História Antiga, portanto, como nas últimas décadas se fortaleceram os grupos de pesquisa e laboratórios, enfim, como funciona, para além da produção, as formas de atuação, de validação de performance e legitimação na área de História. Assim, as ideias de Bourdieu podem levar, num possível aprofundamento ou redirecionamento teórico da pesquisa, a novas possibilidades de abordagem do objeto.

Outro aspecto e a parte final deste comentário refere-se às formas pelas quais podemos pensar a importância da História Escolar para a História Antiga. Gostaria de discutir a importância da disciplina História, lecionada no Ensino Básico, para o mundo acadêmico e também dar um pouco de atenção às formas em que se desenvolvem, hoje, as pesquisas relativas ao Ensino de História Antiga.

Quanto ao primeiro ponto, mais do que uma reflexão prolongada, faço apenas uma afirmação, a de que não parece haver propósito mais relevante em se formar alguém historiador do que o de atuar na formação da juventude, incutindo-lhes não apenas o espírito reflexivo, mas a capacidade de desenvolver a sua própria consciência histórica, o conhecimento da relevância da cidadania, a participação política no mundo contemporâneo, enfim, o seu lugar de agente no futuro do mundo. A despeito dessa relevância crucial, o que vemos é o contumaz descaso das autoridades públicas, seja com as condições estruturais de trabalho, como a qualidade das escolas, seja com a remuneração dos docentes, em geral muito aquém do que se poderia imaginar da relevância desse profissional para a sociedade.

Estou em pleno acordo quando Dominique Santos e os coautores lembram, nas "Considerações Finais", que “[...] em muitos cursos de História, existe separação entre licenciatura e bacharelado, o que cria a falsa impressão de que a pesquisa é hierarquicamente superior ao Ensino e/ou vice-versa”. No 
entanto, os desdobramentos mais interessantes e não plenamente desenvolvidos vieram a seguir no "parágrafo weberiano" - em densidade, duração e, possivelmente, em termos em alemão. Refiro-me ao que menciona a relação antiquada que ainda se estabelece com a Didática da História.

Os autores se baseiam, principalmente, em dois artigos para chamar a atenção a esse problema, o primeiro deles é o de Oldimar Cardoso, publicado em 2008 na Revista Brasileira de História e o segundo, de Rafael Saddi, leitor do primeiro, publicado em 2010, na Revista História \& Ensino.

Concentro-me no discurso de Oldimar Cardoso, que me parece um dos mais interessantes intelectuais brasileiros que se apoia nas ideias oriundas da historiografia alemã recente. Cardoso lembra que no Brasil, frequentemente, a Didática da História é vista como uma área subordinada à educação, sem vínculos necessários com o campo da História e que, dessa maneira, acaba por desconsiderar a cultura escolar, reificando as dicotomias existentes entre elas e um saber erudito, o universitário. Cardoso, inspirado em André Chervel, tenta argumentar que a relação entre saber erudito e cultura escolar é uma via de mão dupla. Desta maneira, pensar a História escolar apenas como uma transposição é simplificação e reducionismo. Não há como não lembrar das importantes reflexões de Carlo Ginzburg, Karen Louise Joly, Hilário Franco Junior, Edward P. Thompson e, até mesmo, Mikhail Bakhtin, que lidaram com a difícil tarefa de trabalhar esse trânsito entre uma cultura popular e uma erudita. Mutatis mutandis, até porque dificilmente poderíamos pensar a História Escolar por meio dessas categorias stricto sensu, isto pode ajudar a pensar também as formas de classificação contemporâneas e como operam os discursos entre o mundo acadêmico e escolar (Saddi, 2010; Cardoso, 2008; cf também Bakhtin, 1999; Jolly, 1996; Franco Júnior, 1996 e 1998; Thompson, 2002; e Ginzburg, 2002).

Nesse sentido, a Didática da História não deveria ser vista como um mero facilitador da aprendizagem, porque não há efetivamente um processo de transferência que devesse ser facilitado, assim, não pode ser considerada como um conjunto de métodos - Unterrichtsmethoden. O caráter prescritivo da Didática da História se esvazia na medida em que se reconhece a autonomia das disciplinas escolares (Cardoso, 2008, p. 157-158), nem mesmo deveria ser vista, em uma perspectiva bastante démodé, como uma espécie de arte de ensinar Lehrkunst. 
Cardoso propõe, portanto, o conceito de Geschichsdidatik, que em suas premissas aproximam tanto Chervel quanto autores ligados à historiografia alemã, tais como: Jörn Rüsen e Hans-Jürgen Pandel. Esse conceito torna a didática indissociável da História e, para além da realidade escolar, ele tem a ver com a própria forma como as pessoas se apropriam e entendem o mundo, conformando a sua própria consciência histórica para a sua orientação em seu cotidiano e no tempo (Cardoso, 2008 p. 159). Numa cultura que toma a historicidade como elemento orientador das práticas (o próprio Rüsen [2010] fala de cultura histórica) essa reflexão é essencial.

Rüsen, por exemplo, acredita que, mesmo a forma científica da História está ligada a esse modo mais genérico de se produzir conhecimento a partir da relação do homem com o "mundo-da-vida" - Lebenswelt -, isto é, com as infinitas possibilidades de relações que se pode estabelecer com os indivíduos e grupos sociais (Weberman, 2009).

Note-se que, segundo Rüsen não se pode dissociar a Didática da História, as formas de apresentação do conhecimento Histórico da Teoria da História. ${ }^{2}$ Assim, "o lugar da pesquisa de campo didático-histórica é o cotidiano das aulas de História ou de qualquer espaço de expressão da cultura ou da consciência histórica" (Cardoso, 2008, p. 162). O trânsito entre a consciência histórica (individual) e uma cultura histórica (coletiva) se parece com as discussões acerca da memória como fenômeno individual e como construção coletiva, mas essa tangente parece demasiada complexa para que a possamos desdobrar em poucas linhas sem parecer um ultraje ao bom-senso. 3

Um dos mais importantes comentários de Oldimar Cardoso, com o qual estou em pleno acordo, é que "A pesquisa de campo didático-histórica não se dirige até a escola para entrevistar professores e alunos, mas para conviver e experiência com eles. (...) não é uma ponte entre dois mundos culturais; ela é uma auto-reflexão sobre a cultura histórica" (Cardoso, 2008, p. 163). Assim, não é possível ser um Historiador de gabinete e nem restringir uma pesquisa apenas ao

\footnotetext{
${ }^{2}$ Eu discuto de maneira mais detida essas questões da consciência histórica em Rüsen em um estudo empírico ainda inédito, cf. Moerbeck (2016), que pode ser encontrado no Academia.edu. Para a consulta ao próprio Rüsen, recomendo Rüsen, 2001 e 2008.

3 Há uma enorme bibliografia, cito apenas Cerri (2013), Ciampi (2012), Halbwachs (2004), Rousso (1998) e Pollack (1992).
} 
cotidiano escolar, mas ampliar o campo de compreensão para a consciência e cultura históricas como um todo.

Em artigo no prelo pude desenvolver uma pesquisa de campo de um ano e meio junto a uma escola da Baixada Fluminense, por meio da qual trabalhei com os alunos dos $6^{\circ}, 7^{\circ}$ e $8^{\circ}$ anos com temas absolutamente relevantes à agenda contemporânea, como: o das clivagens sociais, das relações étnico-raciais e dos discursos religiosos politeístas e monoteístas. Como discutimos aqui muito mais acerca de orientações metodológicas, acabei por me inspirar no trabalho da designer Zoy Anastassakis em sua pesquisa Triunfos e Impasses: Lina Bo Bardi, Aloísio Magalhães e o Design no Brasil. Novamente tomando Bourdieu, a minha reflexão, tanto quanto a da autora que ora menciono, apontam para um tipo de trabalho de caráter etnográfico que explora "não somente a experiência vivida" daquela instituição que de alguma maneira conhecia e era membro permanente, mas as "condições sociais de possibilidade dessa experiência”, inclusive levando em consideração tornar possível a “objetivação da relação subjetiva com o objeto" em busca de resultados mais ou menos palpáveis, comparáveis e que pudessem ser postos sob o escrutínio de meus colegas (Anastassakis, 2014; Bourdieu, 2003b).

Nesse momento, as discussões sobre o Ensino de História navegam com invejável pujança. No entanto, no que tange ao Ensino da História Antiga, ainda caminhamos sôfregos para ampliar e tentar reunir contribuições para consolidar uma área que reflita de maneira permanente e com vínculos fortes com a escola. No próximo ano, em organização com José Maria Gomes de Souza Neto, da Universidade de Pernambuco, e Renan Birro, da Universidade Federal do Amapá, deve vir a público um livro que contará com contribuições de importantes atores da História Antiga, oriundos de diversas instituições e regiões do país. Talvez, esse possa ser um dos primeiros passos para o fortalecimento de uma reflexão mais perene em torno do Ensino de História Antiga.

Há pouquíssimo tempo, após a leitura de uma matéria jornalística em que intervieram os professores do MAE, Vagner Porto e Maria Cristina Kormikiari, pode-se perceber que uma revisão das formas de apresentação do Mundo Antigo tem que ser feita, especialmente no universo editorial didático 
que, em regra, demora a se apropriar da pesquisa em História Antiga no país. 4 Isso ocorre de modo, por vezes flagrante, na maneira como as cidades de Atenas e Esparta se tornaram modelos de leitura para o mundo grego antigo como um todo. Isso não significa dizer que não se possa ou não se deva estudar as cidades em questão, mas, da maneira como é feito hoje por alguns livros didáticos, não é muito diferente do que fizera, com outros propósitos, Jacob Burckhardt em suas palestras, depois tornadas a obra História da Cultura Grega (1999). A despeito da significativa qualidade do autor em questão, estávamos no final do século XIX e, reza a lenda, já estamos no XXI. 


\section{Referências Bibliográficas}

Anastassakis, Zoy. Triunfos e impasses: Lina Bo Bardi, Aloísio Magalhães e o Design no Brasil. Rio de Janeiro: Lamparina, 2014.

Bakhtin, Mikhail. A cultura popular na Idade Média e no Renascimento: $O$ contexto de François Rabelais. São Paulo: Hucitec; Brasília: Editora da Universidade de Brasília, 1999.

Barnabé, Luís Ernesto. Justiniano José da Rocha e os primeiros manuais de História Antiga na escolarização brasileira. In: IX Encontro Nacional de História Antiga do GTHA, 2016.

Bourdieu, Pierre. A economia das trocas simbólicas. Trad. Sérgio Miceli et al. São Paulo: Perspectiva, 2003a.

. L'observation participant. In: Actes de la recherche em Sciences Sociales. $\mathrm{n}^{\mathrm{0}} 15 \mathrm{O}$, p. 43-57, $2003 \mathrm{~b}$.

Bertrand Brasil, 2004.

O poder simbólico. Trad. Fernando Tomaz. Rio de Janeiro: . O senso prático. Petrópolis: Vozes, 2009.

. A economia das trocas linguísticas: O que falar quer dizer. Trad. Sérgio Miceli et al. São Paulo: Edusp, 2010.

Burckhardt, Jacob. The Greeks and Greek civilization. Translated by Sheila Stern. New York: St. Martin's Griffin, 1999.

Cardoso, Oldimar. Para uma definição de Didática da História. Revista Brasileira de História (São Paulo), vol. 28, n. 55, 2008.

Cerri, Luis Fernando. Ensino de História e consciência histórica. Rio De Janeiro: FGV, 2013.

Ciampi, Helenice. Os desafios da História local. In: Monteiro, Ana Maria et al. (orgs.). Ensino de História: sujeitos, saberes e práticas. $3^{\text {a }}$ ed. Rio de Janeiro: MAUAD X, 2012, p. 199-214.

Domingues, José Maurício. Teorias sociológicas do século XX. Rio de Janeiro: Civilização Brasileira, 2008.

Faversani, Fábio; Campos, Carlos Eduardo da Costa. Prof. Fábio Faversani ressalta o crescimento dos estudos da antiguidade no Brasil. (Entrevista). Philía: Jornal Informativo de História Antiga (Rio de Janeiro), ano XII, n. 32, nov./dez., 2009.

Florenzano, Maria Beatriz Borba. Classicismo e Coleções de Moedas no Brasil. In: Chevitarese, A; Cornelli, G.; Silva, M.A. (Orgs.). A Tradição Clássica no Brasil. Brasília: Fortium Editora, 2008, p. 159-170.

Franco Júnior, Hilário. A Eva barbada: ensaios de mitologia medieval. São Paulo: Edusp, 1996.

Companhia das Letras, 1998.

- Cocanha: A história de um país imaginário. São Paulo: 
Funari, Pedro Paulo de Abreu; Garraffoni, Renata. História Antiga na Sala de Aula. Col. Textos Didáticos, n. 51. Campinas: IFCH/UNICAMP, 2004.

Ginzburg, Carlo. O queijo e os vermes. São Paulo: Companhia das Letras, 2002.

Gonçalves, Ana Teresa Marques; Silva, Gilvan Ventura da. O Ensino de História Antiga nos livros didáticos brasileiros: balanço e perspectivas. In: Chevitarese, A; Cornelli, G.; Silva, M. A. (Orgs.). A Tradição Clássica no Brasil. Brasília: Fortium Editora, 2008, p. 21-34.

Goody, Jack. O roubo da História: Como os europeus se apropriaram das ideias e invenções do oriente. São Paulo: Editora Contexto, 2008.

Halbwachs, Maurice. A Memória Coletiva. São Paulo: Ed. Centauro, 2004.

Jolly, Karen Louise. Popular religion in late Saxon England: Elf charms in context. North Carolina: The University of North Carolina Press, 1996.

Moerbeck, Guilherme. Entre a religião e a política: Eurípides e a Guerra do Peloponeso. No prelo.

. Clivagens sociais e relações étnico-raciais: um estudo sobre a consciência histórica nos $7^{\circ}$ e $8^{\circ}$ anos do Ensino Fundamental. Artigo inédito, 2016.

Pollack, Michael. Memória e Identidade Social. In: Estudos Históricos, vol. 5, n. 10, 1992.

Rousso, H. A Memória não é mais o que era. In: Ferreira, M. M.; Amado, J. (Orgs.). Usos e Abusos da História Oral. Rio de Janeiro, FGV, 1998.

Rüsen, Jörn. Razão Histórica - Teoria da História: os fundamentos da ciência histórica, vol. I. Brasília: UnB, 2001.

. História Viva: Teoria da História III - Forma e funções do conhecimento histórico, vol. III. Brasília: UnB, 2008.

Narrativa História: fundamentos, tipos, razão. In: Schmidt, Maria Auxiliadora; Barca, Isabel; Martins, Estevão R. Jörn Rüsen e o ensino de História. Trad. Marcelo Fronza. Curitiba: Ed. UFPR, 2010, p. 93-108.

Saddi, Rafael. Didática da História como Sub-Disciplina da Ciência Histórica. História \& Ensino (Londrina), vol. 16, n. 1, 2010, p. 61-80.

Silva, Semíramis Corsi. Aspectos do Ensino de História Antiga no Brasil: Algumas Observações. Alétheia: Revista de estudos sobre Antiguidade e Medievo, vol. 1, jan.-jul., 2010.

Thompson, E. P. Costumes em Comum: Estudos sobre a cultura popular tradicional. São Paulo: Companhia das Letras, 2002.

Weberman, David. Phenomenology. In: Tucker, Aviezer (org.). A Companion to the Philosophy of History and Historiography. Blackwell Publishing, 2009, p. 508-518. 